\title{
Public Awareness of Colorectal Cancer Screening: Knowledge, Attitudes, and Interventions for Increasing Screening Uptake
}

\author{
Antonio Z. Gimeno Garcia, ${ }^{1,2}$ Noemi Hernandez Alvarez Buylla, ${ }^{1}$ \\ David Nicolas-Perez, ${ }^{1}$ and Enrique Quintero ${ }^{1}$ \\ ${ }^{1}$ Servicio de Aparato Digestivo, Hospital Universitario de Canarias, Unidad de Endoscopia, La Laguna, 38320 Tenerife, Spain \\ ${ }^{2}$ Departamento de Gastroenterología, Hospital Universitario de Canarias, Unidad de Endoscopia, Ofra s/n, La Laguna, \\ 38320 Tenerife, Spain
}

Correspondence should be addressed to Antonio Z. Gimeno Garcia; antozeben@gmail.com

Received 8 December 2013; Accepted 31 December 2013; Published 5 March 2014

Academic Editors: L. Saragoni and G. Schiavon

Copyright (c) 2014 Antonio Z. Gimeno Garcia et al. This is an open access article distributed under the Creative Commons Attribution License, which permits unrestricted use, distribution, and reproduction in any medium, provided the original work is properly cited.

\begin{abstract}
Colorectal cancer ranks as one of the most incidental and death malignancies worldwide. Colorectal cancer screening has proven its benefit in terms of incidence and mortality reduction in randomized controlled trials. In fact, it has been recommended by medical organizations either in average-risk or family-risk populations. Success of a screening campaign highly depends on how compliant the target population is. Several factors influence colorectal cancer screening uptake including sociodemographics, provider and healthcare system factors, and psychosocial factors. Awareness of the target population of colorectal cancer and screening is crucial in order to increase screening participation rates. Knowledge about this disease and its prevention has been used across studies as a measurement of public awareness. Some studies found a positive relationship between knowledge about colorectal cancer, risk perception, and attitudes (perceived benefits and barriers against screening) and willingness to participate in a colorectal cancer screening campaign. The mentioned factors are modifiable and therefore susceptible of intervention. In fact, interventional studies focused on average-risk population have tried to increase colorectal cancer screening uptake by improving public knowledge and modifying attitudes. In the present paper, we reviewed the factors impacting adherence to colorectal cancer screening and interventions targeting participants for increasing screening uptake.
\end{abstract}

\section{Introduction}

Colorectal cancer (CRC) is the fourth leading cause of death worldwide causing approximately 608.000 deaths in 2008 and $8 \%$ of all cancer related deaths. CRC also ranks as the third more incidental cancer accounting for 1.2 million new cases in 2008 [1].

In this way, professional organizations have published screening recommendations to guide clinical practice in average-risk population as well as in relatives (FDR) of patients with CRC [2-4]. Currently, annual or biannual fecal occult blood test (FOBT), colonoscopy every 10 years, and rectosigmoidoscopy every 5 years are the most frequent strategies. Evidence clearly suggests that CRC screening with any of the three recommended tests reduces CRC mortality [5-8]. However, high rates of participation are mandatory for the success of any screening campaign in terms of mortality reduction and cost effectiveness, particularly for those screening strategies requiring shorter screening intervals to be effective (such as the FOBT) [9].

Unfortunately, despite the efficacy of CRC screening in reducing incidence and mortality rates, screening uptake remains behind that of other screening-amenable cancers and rates continue to be low worldwide [10, 11]. Although, the American Cancer Society suggested a 75\% screening uptake as an acceptable goal, current screening rates according to the recent published data of the National Health Interview Survey barely caught up the $58 \%[12,13]$. Conversely, a recent report of the European Commission proposed $45 \%$ as the minimum participation rate, although $65 \%$ has been recommended [14]. However, current participation rates are far from that 
goal ranging from $20 \%$ to $52 \%$ in those countries with an organized screening programme [15].

A bunch of factors of screening compliance have been reported over the last two decades of research [16]. Those factors can be grouped in patient level factors, including sociodemographic and psychosocial factors and healthcare system and provider factors [16].

In the same way, interventions for increasing CRC screening uptake have focused on different levels including patients, subjects in the workplace and community-based settings, and healthcare systems and providers. The present review is focused on patient factors and interventions targeting patients for increasing CRC screening uptake.

\section{Factors Impacting Patient Adherence}

The research on the factors that influence health behaviours (i.e., screening uptake) is of great importance when we are dealing with low rates of screening participation. A broad understanding of those factors is crucial to explain health behaviours and may provide a foundation for wellinformed public health programs. It may also contribute to the design of more efficient intervention strategies in order to change screening behaviours [71]. Much research has been performed on factors that predict the likelihood of CRC screening $[71,72]$. Those factors can be classified as nonmodifiable (i.e., patient characteristics) and modifiable. Although most studies have been focused on patient characteristics, modifiable factors may be much more interesting as they are susceptible to be changed. Theories of health behaviour or theoretical models have been developed to understand why people do or do not practice different health behaviours, identifying modifiable factors which may be plausible targets of interventional strategies [73, 74]. Therefore, theoretical models have a dual purpose, "explanatory" and "interventionist." Nonmodifiable factors include demographics (age, sex, race, ethnicity, and marital status), income, educational level, medical insurance, family history, healthy behaviours (i.e., screening for other cancers) or risky behaviours (i.e., toxic habits, sedentary life), and access to care (i.e., proximity to healthcare facilities, a regular source of care) $[9,75]$. Conversely, modifiable ones include patient knowledge about CRC and screening, attitudes (i.e., perceived benefits of screening and barriers against screening), and perception of risk for developing a CRC [76, 77].

The studies investigating predictive factors usually assessed the outcome of CRC screening using the recommended intervals proposed by the different medical societies for the screening in the average-risk population: FOBT in the last 1 or 2 years, colonoscopy within the past 10 years, or rectosigmoidoscopy within the past 5 years.

Recently, the 2010 NHIS survey on the use of CRC screening in the recommended intervals and individual related factors of screening participation in USA has been published [12]. The factors tested in this survey included mostly nonmodifiable factors. There were statistically significant differences $(P<0.05)$ in use in terms of age, race, education, income, type of healthcare insurance, usual source of healthcare, and family history of CRC. Others like physician recommendation $[78,79]$ and utilization of other preventive health services $[80,81]$ have been reported in several studies.

Screening rates gradually increased from 50 to 70 years. This relationship is in keeping with previous analysis reported by the NHIS in 2000 and 2005 [82, 83]. This finding could be explained because Medicare covers CRC screening in people older than 65 years. However, mixed results were found in recent European studies and therefore other factors may interfere with this association $[18,84]$. For instance, whereas in a recent Spanish study carried out in nonselected participants older than 50 years [84], past screening uptake was higher among people younger than 65 years, in a randomized study performed in Italy [18], participants aged 65 years or older experienced higher rates of screening. Disparities have been found in some racial minorities in the USA. Although NHIS reports published in the last decade (including the last one) did not find any difference between whites and blacks, other minorities such as Asians and American Indians were less likely to report being screened than whites $[12,83]$. In the same way, lower screening rates are consistently reported for Hispanics [85]. Cultural factors, low income, low-educational level, and the lack of healthcare insurance are known barriers against screening, being more prevalent in minority groups $[85,86]$.

Most studies agree that CRC screening is increased in highly educated participants. Literacy has been used as a variable to explain the impact of education on health behaviour in general and screening participation in particular $[87,88]$. These findings are similar in European and in US studies $[43,85,89]$. As the educational level is usually lower in racial/ethnic minorities, low-income groups, and those without health insurance, these variables have been advocated as potential modifiers [90,91]. One of the most important factors for predicting participation is socioeconomic deprivation, highlighted by the recent NHIS survey showing a progressive participation with a higher annual family income [12]. The importance of this factor is closely related to insurance status. In the NHIS survey, people with any type of insurance (private, military without private, and only government/public) were more likely to report being screened than those without. This factor is more important in countries in which health services are not government founded. Access of care defined as usual or regular source of care has been associated with higher rates of screening uptake. The pivotal role of primary care physician (PCP) for recommending and increasing CRC screening is well established [92, 93]. In a nationwide US survey conducted by the National Center for Health Statistics [12], 62\% of those with usual source of care reported use of any test within the recommended intervals compared with only $22.4 \%$ without. This factor is in accordance with results in European studies [43]. Uninsured people might not have a regular healthcare provider and subsequently, they may not receive a referral for testing.

Several studies suggested that individuals with a family history of CRC are more likely to engage in screening than the average-risk population $[9,94]$. In two recent studies carried out in Spain including 953 consecutive average-risk 
individuals and 334 relatives of patients with CRC [43, 95], $13 \%$ and $22 \%$, respectively, had undergone a CRC screening test and only in $1 \%$ and $8 \%$, respectively, the indication was screening. A subjective perception of higher risk of developing CRC was one of the most important predictors in the multivariate analysis [95]. Controversial results were obtained regarding gender across the studies. Although, in general, men have been more willing to participate than women [82, 96], recent data suggest that gender gap in CRC screening may be decreasing [12]. Marital status was consistently associated with CRC screening, either in USA or in Europe [82, 83, 97]. A large European study [97], controlled by age and educational level, showed a higher participation in married people and observed that invitations of both partners increased participation rates.

Health behaviours not related to CRC screening have been associated with CRC screening uptake $[82,83,98]$. A recent large multicenter study conducted in 15.000 adults aged 50-74 years in USA [98] assessed the risk factors of nonparticipation. In that study, nonwhite participants, with a low educational level, current smokers, and those who had lower rates of cancer screening (such as use of mammography, pap screening tests, or prostate-specific antigen test) were more likely to be nonparticipants.

The lack of knowledge about CRC and screening was reported as a prominent barrier for screening adherence $[30,82,99]$. Some authors suggested that it is more important in areas where screening is opportunistic [100]. Furthermore, knowledge about CRC has proven to be an independent predictor of positive attitudes toward screening, and both knowledge and attitudes are correlated with intention to be screened [101, 102]. Lack of knowledge is linked to low levels of education, minority ethnic groups, lack of health insurance, and low household income $[76,103,104]$. Different items have been used for assessing the level of knowledge, including signs and symptoms of CRC, risk factors, incidence, prognosis, and awareness of screening methods. In different studies carried out by the NHIS, the lack of knowledge of either FOBT or endoscopy as a screening test was a barrier, being reported by half of the participants $[12,82]$.

In a prospective study conducted in 953 average-risk participants [43], knowledge of CRC signs or symptoms was the strongest predictor for either having ever used a screening test (OR 6.46, CI 95\% [4.28-9.74]) or being up-to-date with CRC screening (OR 7.23, CI 95\% [4.36-11.98]).

Among the theoretical models of the health behaviour process, the Health Belief Model (HBM) remains one of the most popular models [72]. It has been used to examine cancer screening and other preventive behaviours as well as associations between health beliefs and the willingness to seek cancer screening services $[105,106]$. The HBM measures people's beliefs regarding their risk for a health problem. According to this perception, HBM estimates the probability to take action to prevent, control, or screen for a disease and identifies specific constructs that may influence this behaviour [71]. The key constructs of perceived susceptibility and severity, perceived benefits and barriers, cues to action, and the more recent addition of self-efficacy, are the core constructs of the HBM. All these constructs are extremely interesting, as they are plausible targets of intervention.

High-risk perception has been cited frequently as a predictor of CRC screening. For instance, in a large representative sample of UK [107], participants who answered that their risk was higher than the average-risk population were more willing to participate in CRC screening (98\%) than those who answered with the same risk (84\%). In a Spanish study carried out in family-risk population [95], a high subjective perception of risk was an independent predictor for CRC screening (odds ratio $=2.87,95 \%$ confidence interval: 1.10 7.46; $P=0.03$ ). In another study [108], a higher perception of risk among relatives of patients with CRC increased with the number of relatives with CRC.

Negative attitudes or barriers such as anxiety, embarrassment, disinterest, fear of cancer or screening tests, lack of time, feeling healthy, subjective perception of pain or danger, discomfort, apprehensions about bowel preparation, and laxatives or insertion of the scope have been described across the studies [76, 109-111].

Conversely, potential participants with positive attitudes or perceived benefits of screening are more willing to participate in screening behaviours. Some of them include early cancer detection, regular checkups, or screening help to calm someone down [110].

A recent study conducted in Spain in average-risk population [110] showed that negative attitudes were more important than benefits in the health behaviour process. In that study, fear of CRC or screening tests and embarrassment were the main barriers that contributed to a low participation rate.

A systematic review about barriers and facilitators of CRC screening showed that the most commonly reported barriers related to screening tests were unpleasantness, discomfort, or perceived risk associated with performing the tests [112].

\section{Interventions}

We carried out a review searching in the PubMed and Cochrane library. The following MESH terms were used: "intervention," "improvement," "promotion," "increasing," and "colorectal cancer screening." Inclusion criteria included (1) English language, (2) full manuscript publication, (3) CRC screening behaviors defined as completion of any CRC screening test, (4) randomized controlled trials comparing any type of intervention with the usual care or with other interventions; systematic reviews and the articles included as well as articles from references were retrieved; an additional search of manuscripts after the date of publication of the systematic reviews was performed, and (5) published before August, 2012.

The types of interventions focused on participants to increase CRC screening were selected according to the Guide to Community Preventive Services, and they included the following [113]:

(i) participant reminders: they included any material used to remind participants that they are due for CRC screening. Generally, reminders consisted of printed 
material (generally a mailed letter or postcard) or telephone messages;

(ii) small media: informational or educational material delivered in pamphlets, brochures, leaflets, newsletters, letters, calendars, flip charts, or video about screening;

(iii) one-to-one education: delivering information or providing motivation in an individual setting by health professionals or trained people (i.e., peer coaches and patient navigators);

(iv) group education: delivering information about benefits, indications, and how to overcome barriers to screening and providing motivation in a group setting (usually lowincome communities or racial/ethnic minorities) by a health professional or trained people;

(v) reduction of structural barriers or reducing out-ofpocket costs: focused on decreasing economic and noneconomic obstacles to screening. They try to overcome access burdens (i.e., providing free transportation to patients, maildelivered FOBT, or free assistance by trained people, patient navigators);

(vi) incentives: rewards that motivate people to accept or seek cancer screening. Although this category is also included, no RCT was found.

In most of the studies, several interventions were actually a combination of two or more interventions, specially, oneto-one or group interventions with small media or reminders or small media with reminders. So, it was difficult to assess the effect of each individual intervention in CRC screening behaviour. Studies from each category are compiled in Tables 1 to 5 .

3.1. Patient Reminders. Twelve RCT were qualified for inclusion (Table 1) [17-28]. Most studies used more than one intervention for increasing participation rates. In brief, 10 used a combination of small media material and reminders $[17-25,27]$. In 2 of them strategies to overcome structural barriers were also included $[22,26]$, and in 1 study one-to-one education strategy was included [26]. Only 1 study used just reminders [28], whereas in the study by Coronado et al. and Sequist et al. up to 2 different strategies along with reminders were used (strategies to overcome structural barriers plus one-to-one education and strategies to overcome structural barriers plus small media, resp.) $[22,26]$. In 4 studies the outcome was just adherence to $\operatorname{FOBT}[20,21,23,26]$, in 5 adherence with any CRC screening tests [17, 22, 24, 25, 27], in 2 colonoscopy completion rate $[19,28]$, and in 1 either flexible sigmoidoscopy or FOBT screening [18]. Overall the intervention using reminders increased participation in 8 studies $(67 \%)$ ranging the effect compared with the usual care group from $5.7 \%$ to $35.7 \%[17,19,20,22,23,25,26,28]$.

3.2. Small Media. Thirty RCT using small media based interventions for increasing participation rate were retrieved (Table 2) [17-25, 27, 29-32, 34-42, 44-48, 110, 114]. The studies by Ruffin et al. [41], Dolan and Frisina [32], Marcus et al.
[38], Segnan et al. [18], Doorembos et al. [27], and Lipkus et al. [37] compared different small media strategies without the inclusion of a usual care group. In 3 of the 6 studies, a trend was found with the increased number of interventions $[37,38,41]$, but no significant difference was found in the rest. In the remaining studies, small media interventions were compared with usual care. In 10 of these studies, several small media strategies were combined including educational leaflets, brochures, calendars, booklets, or videotapes [20, 21, $24,25,30,31,34,35,44,47]$. However, only in 4 of them (40\%), at least one intervention group had a positive effect on participation $[20,25,30,35]$. In the studies in which only one media intervention was used, 2 (29\%) increased participation rate $[33,110]$. Small media were combined with another strategy in 10 studies, in 5 of them only with reminders $[19,21,24,25,48]$, in one with overcoming structural barriers [29], and in another one with one-to-one education [35]. In 3 studies, small media, overcoming structural barriers, and reminders were used altogether $[17,22,23]$. In $6(60 \%)$ of the RCT, with a combination of small media with another strategy, the intervention had a positive effect on screening participation $[17,19,22,23,25,35]$.

Overall, in 12 studies (50\%), participation rate was higher in the intervention group than in the usual care group $[17,19$, $20,22,23,25,30,33,35,41,46,110]$.

3.3. One-to-One Education. Fifteen RCT assessed the benefits of one-to-one strategy on screening participation rate (Table 3) [26, 42, 45, 46, 49-58, 115]. Trained health educators, patient navigators, community health workers, or health professionals (i.e., nurses or GPs) participated across the studies. In most of the studies, one-to-one strategy was combined with another one (in 5 studies with small media $[49,51,52,58,115]$, in 2 studies with overcoming barrier strategies $[55,57]$, in three studies with both $[42,46,54]$, and in 2 studies with overcoming barriers and reminders) $[26,53]$. In 9 of the studies, the intervention was compared with usual care $[42,45,46,50,52,55,56,58]$. In 6 of them $(67 \%)$, the intervention increased participation rates compared with usual care $[42,46,50,52,55,56]$.

Overall, in 12 of the RCT $(80 \%)$, the intervention increased participation rates [26, 42, 46, 50-57, 115].

3.4. Group Education. Six RCT used group education strategies, usually focused on low-income communities or ethnic/racial minorities (Table 4) $[35,57,59-62]$. In all the studies, another strategy was included, usually a small media intervention. Only in 3 studies, it was compared with usual care $[35,59,61]$. All of them showed a significant benefit of the intervention.

Overall, 5 studies (83\%) showed a positive effect of the group educational intervention $[35,57,59,61,62]$.

3.5. Reduction of Structural Barriers and Out-of-Pocket Costs. Nineteen studies assessed the usefulness of the reduction of structural barriers/out-of-pocket costs on CRC screening participation (Table 5) [17, 18, 22, 26, 42, 46, 50, 53-55, 57, 63-70]. Free posted FOBTs, prepaid postage, and assistance 


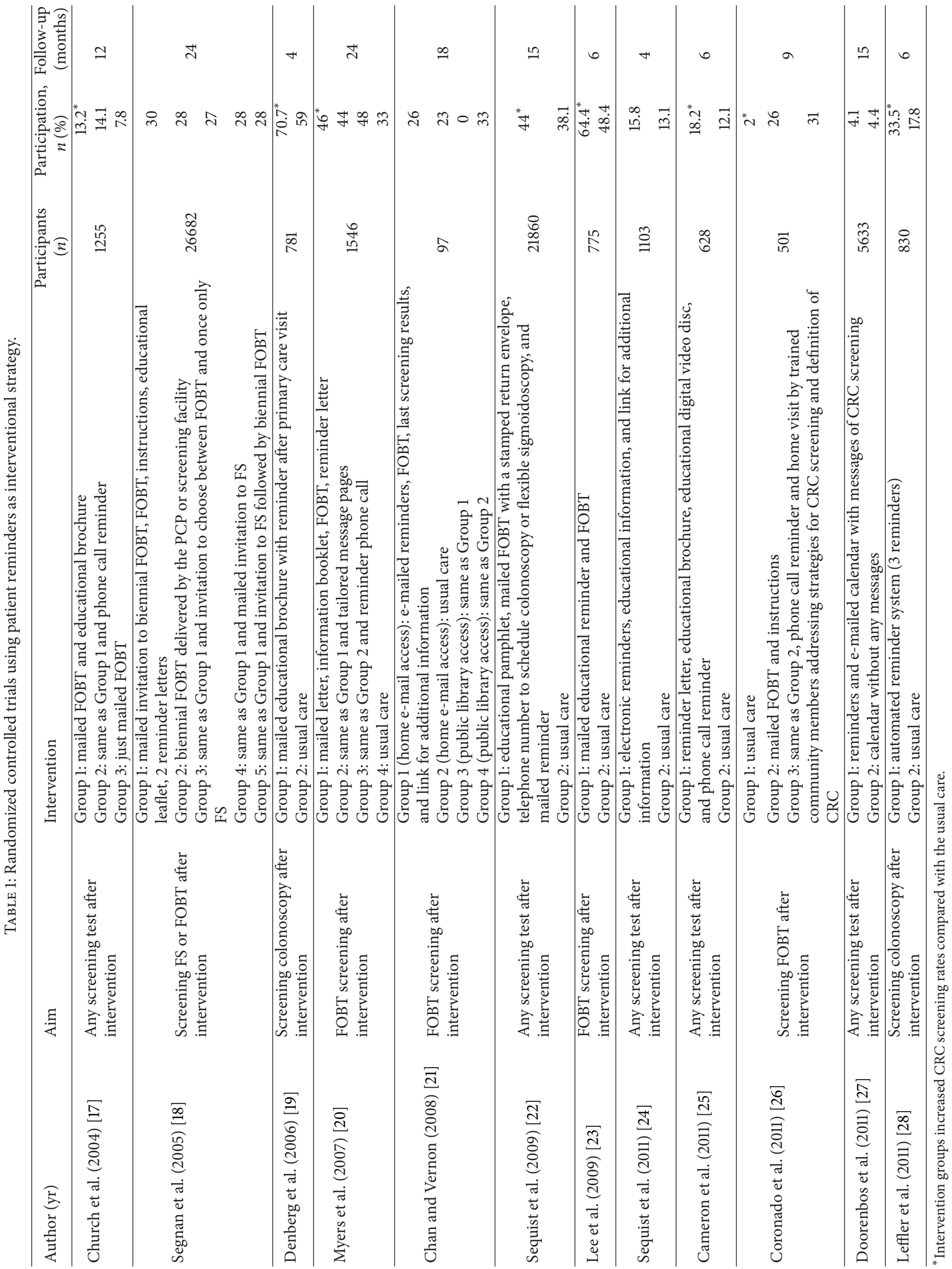




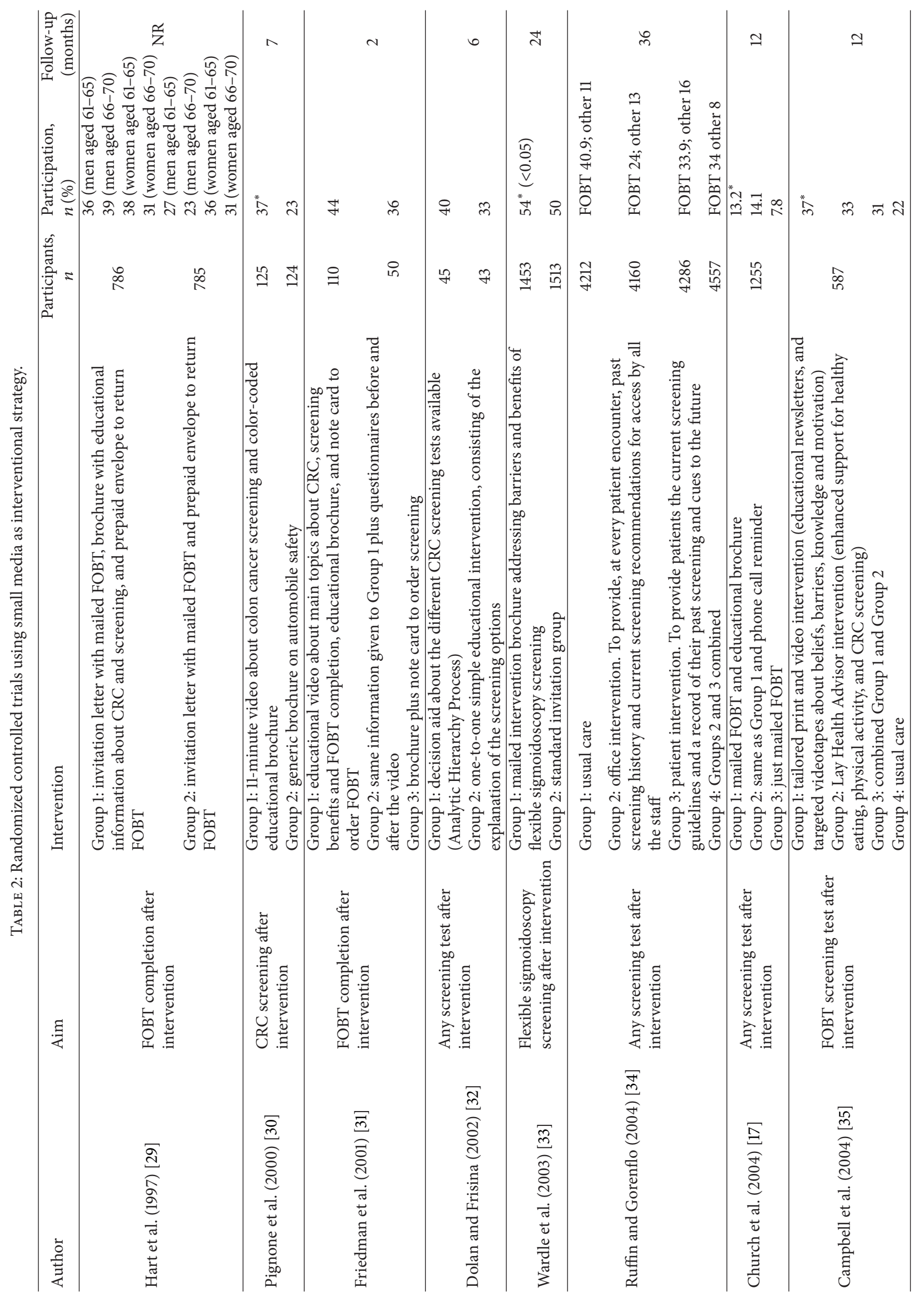




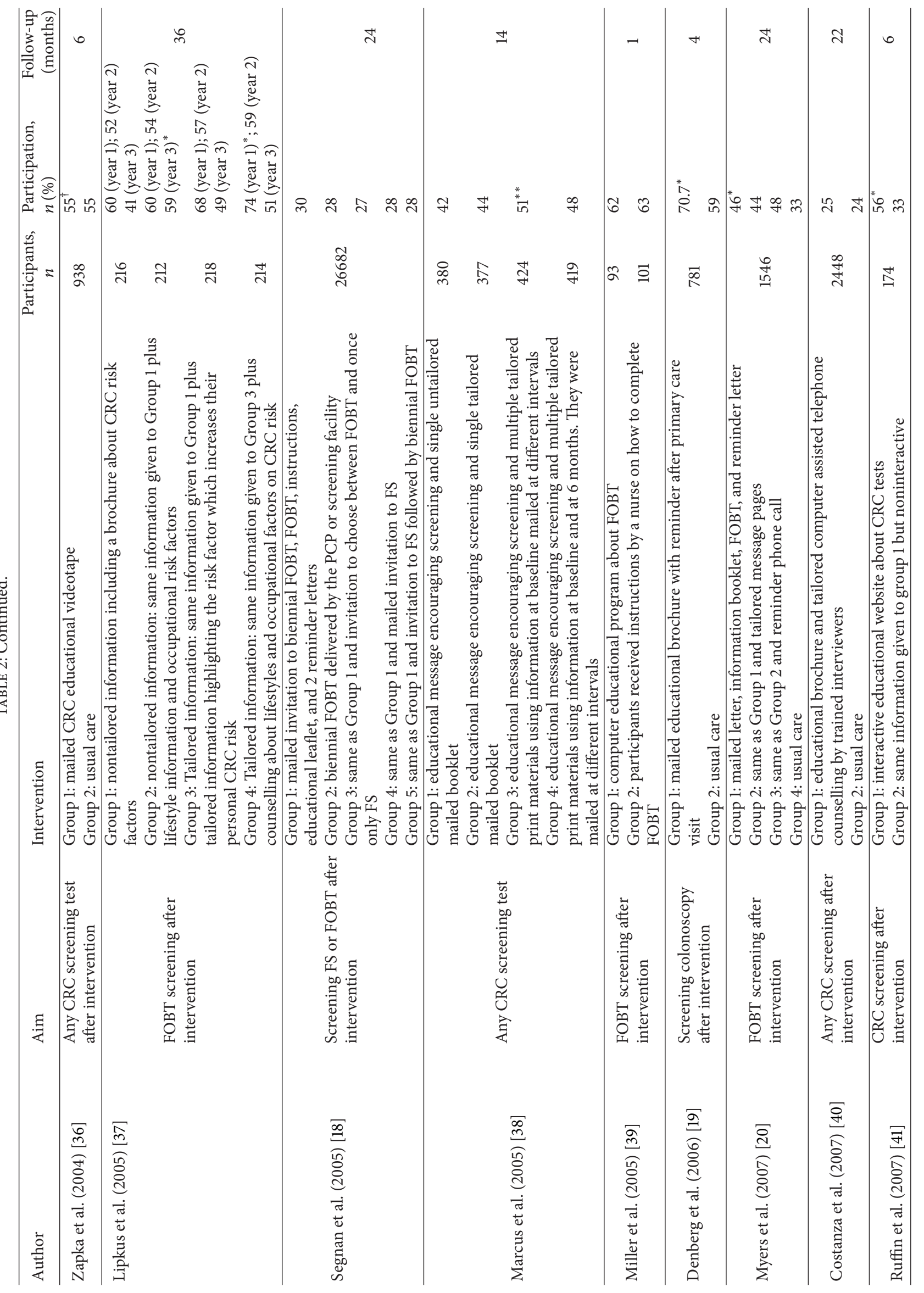




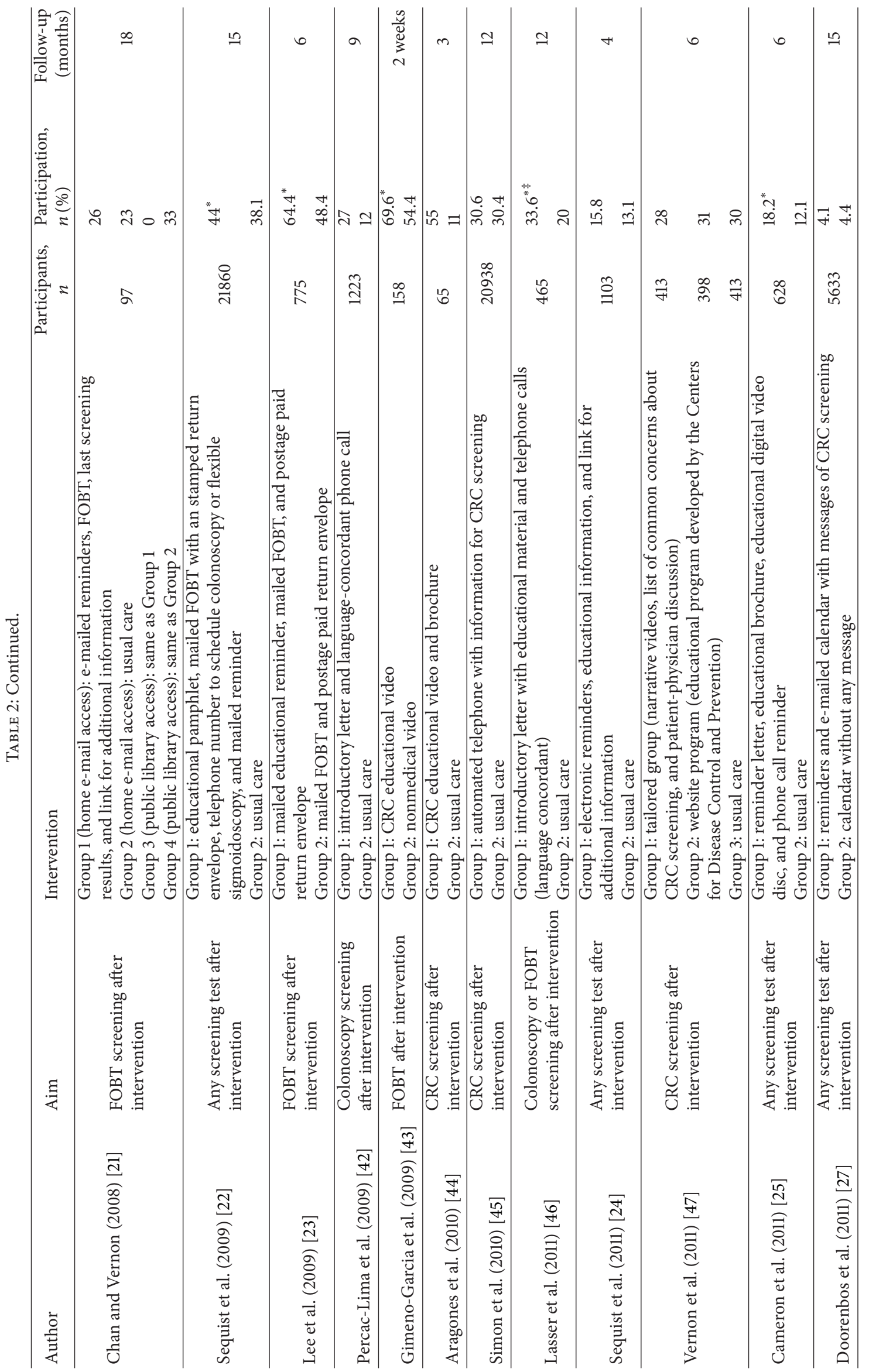




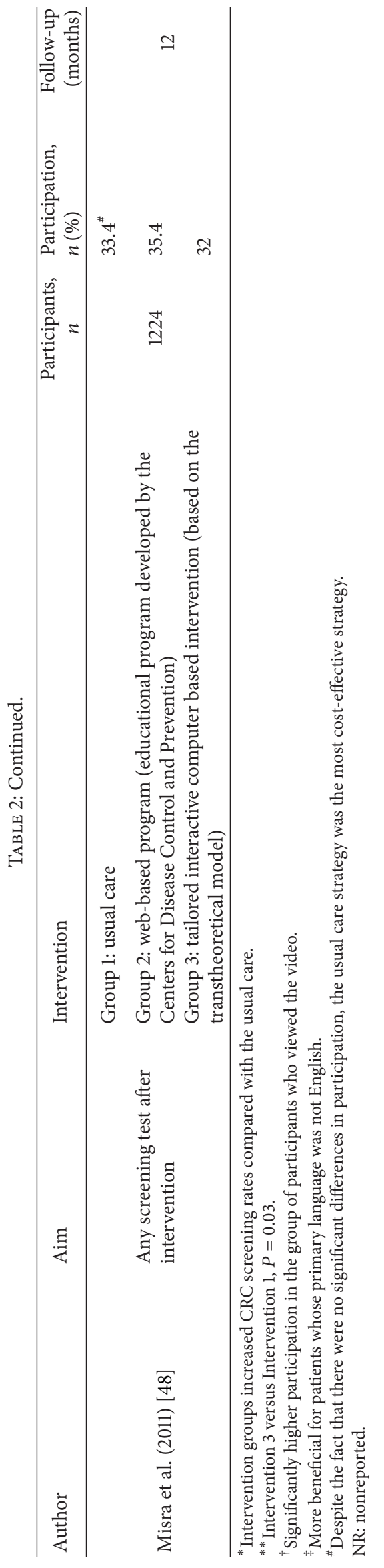




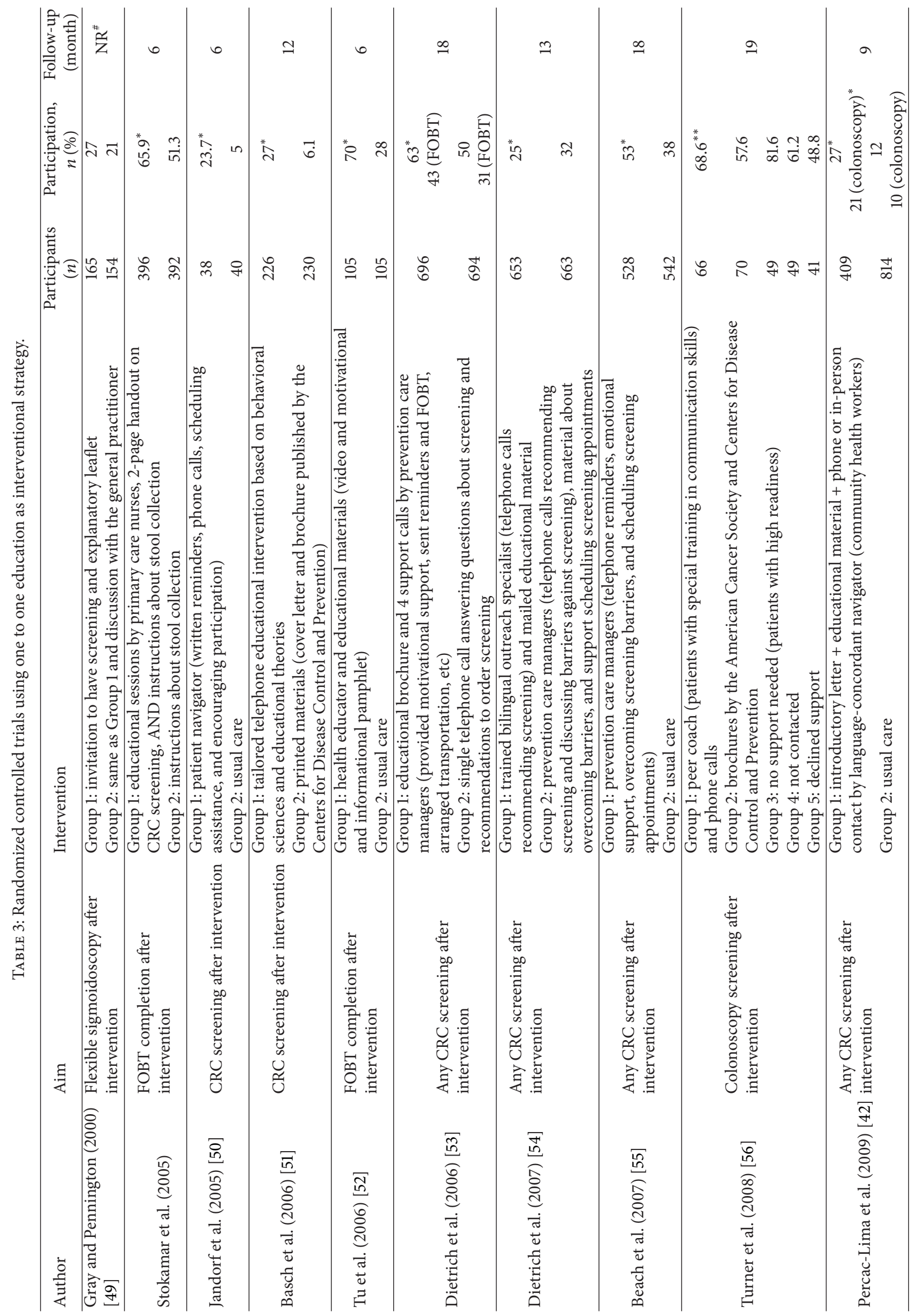




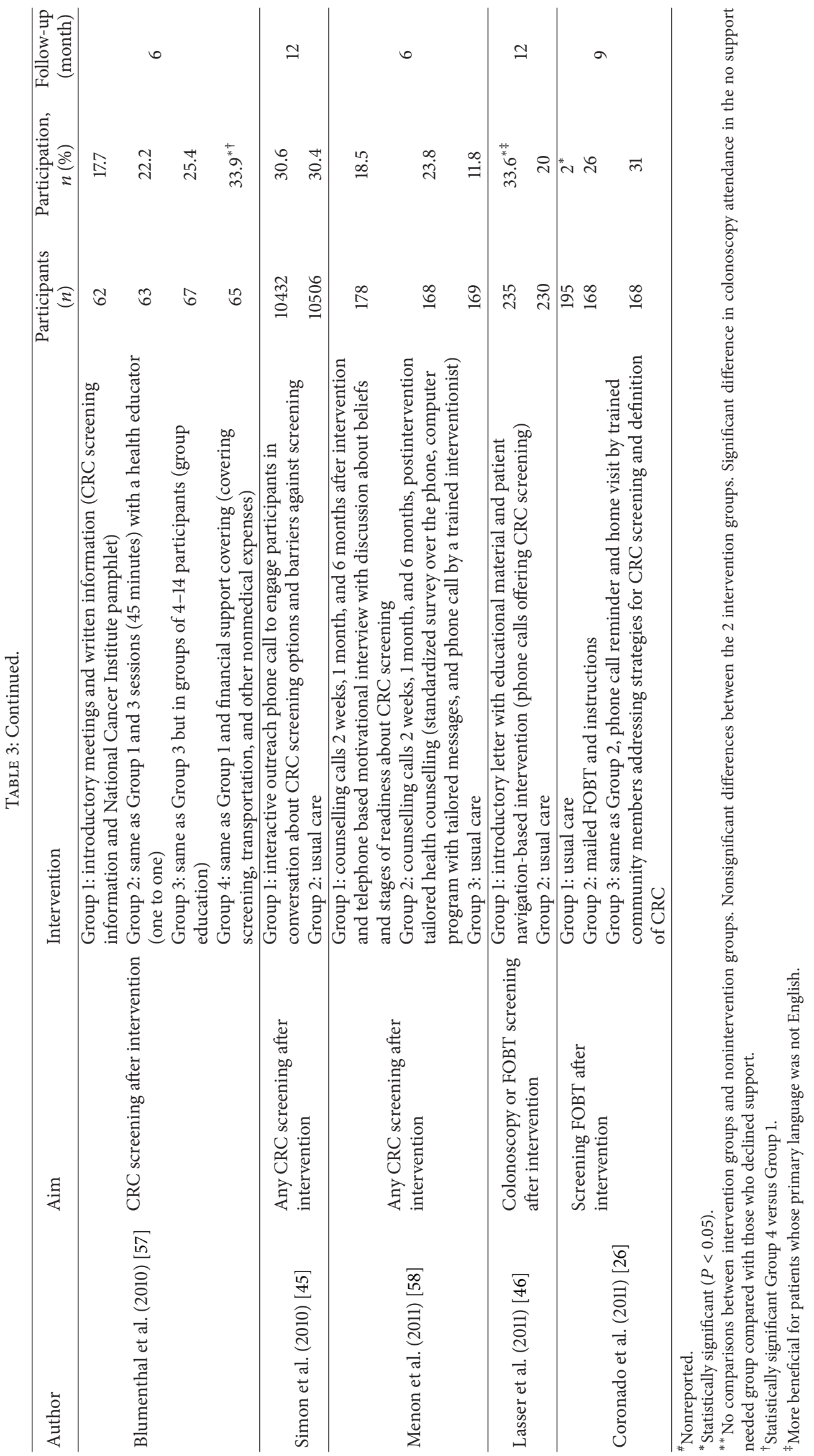




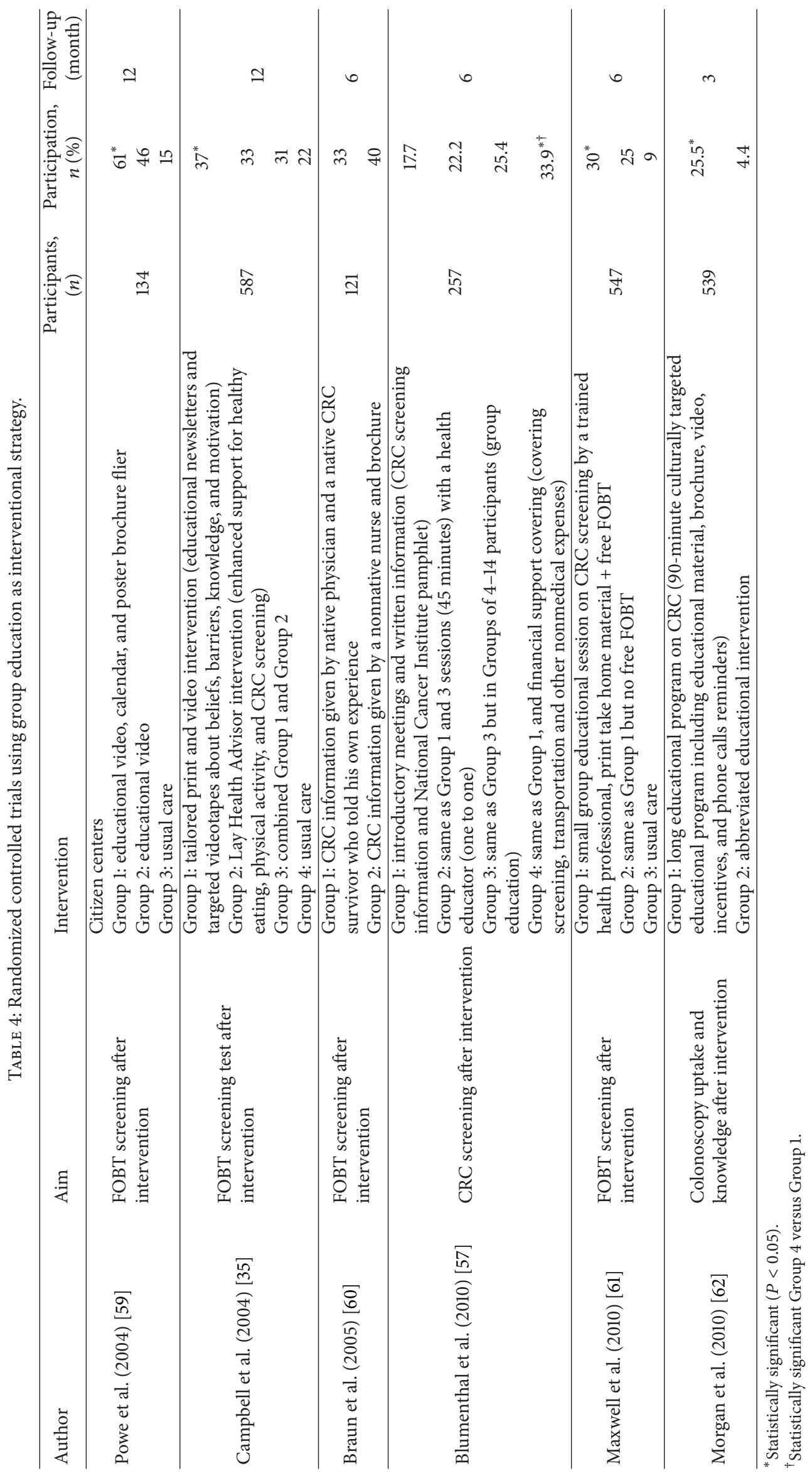




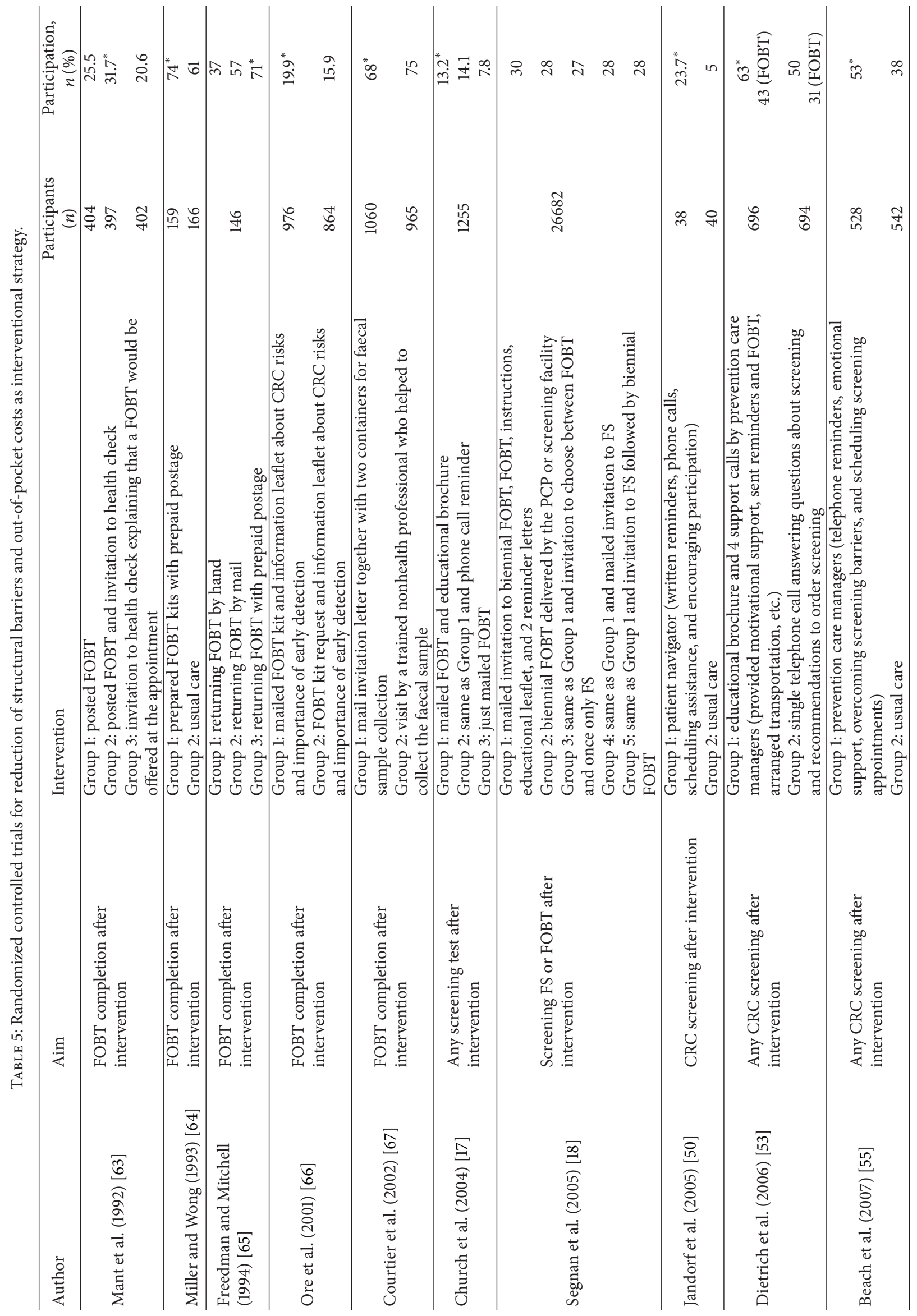




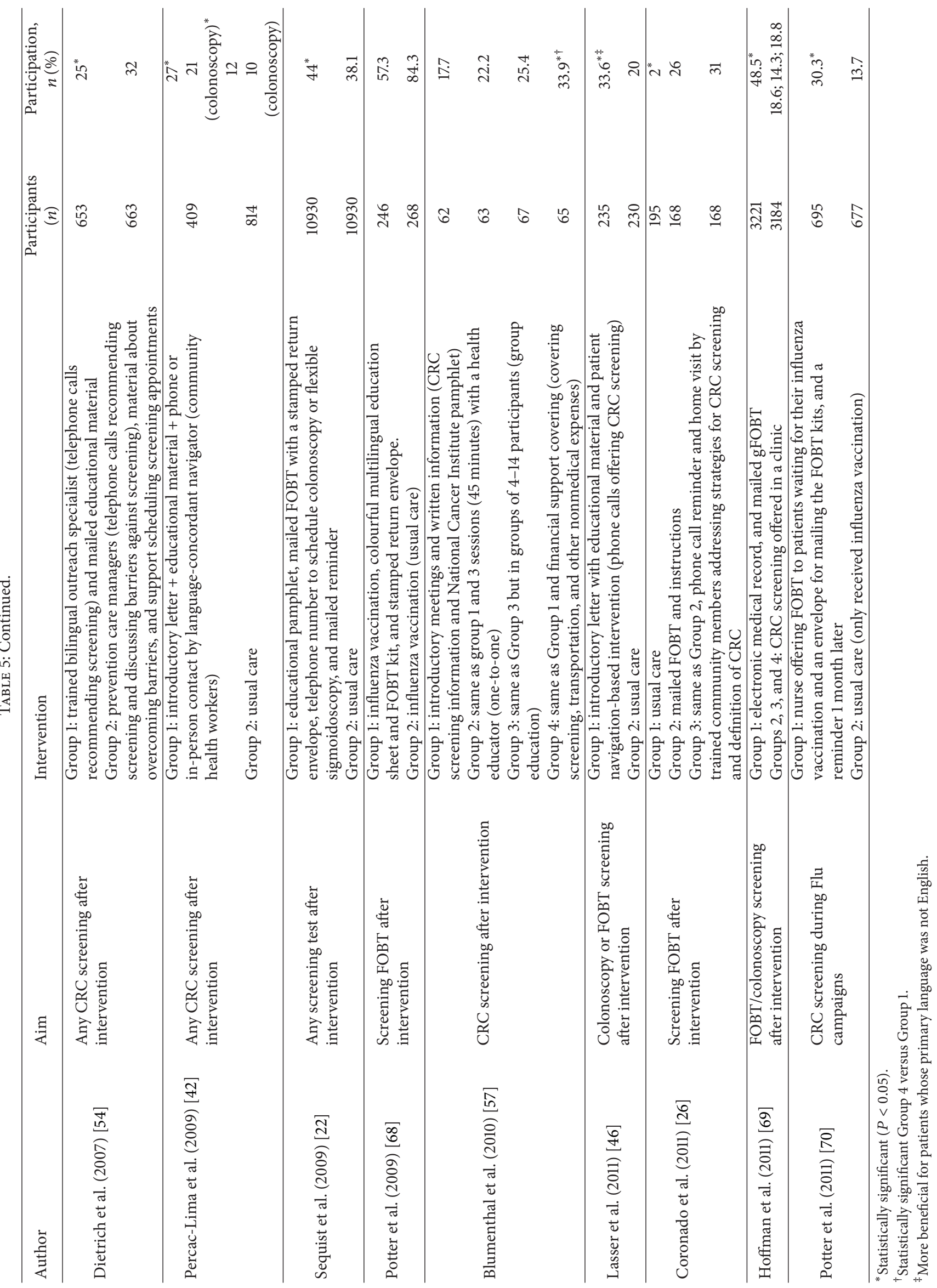


provided by health or nonhealth trained people (i.e., patient navigator, prevention care managers, or community health workers) were the most frequent strategies used. Fourteen studies combined different strategies, mainly with small media and/or reminders $[17,18,22,26,42,46,50,53-55,57$, $63,66]$.

Ten of them compared this intervention with usual care $[22,26,42,46,50,55,64,68-70]$. All of them showed a positive effect of the intervention (Table 1). Overall, only one study did not find significant differences in favour of the intervention [18].

\section{Conclusion}

High participation rates are of utmost importance for the success of any screening campaign. Efforts are needed to figure out modifiable and nonmodifiable factors impacting adherence in each specific population. Knowledge of modifiable factors is gaining special interest in order to design specific interventions. Educational interventions (one-to-one or group interventions), reminders encouraging screening, and interventions based on reduction of structural barriers and out-of-pocket costs seem to be the most effective patient level interventions for increasing participation rates.

\section{Conflict of Interests}

The authors declare that there is no conflict of interests regarding the publication of this paper.

\section{References}

[1] J. Ferlay, H.-R. Shin, F. Bray, D. Forman, C. Mathers, and D. M. Parkin, "Estimates of worldwide burden of cancer in 2008: GLOBOCAN 2008," International Journal of Cancer, vol. 127, no. 12, pp. 2893-2917, 2010.

[2] A. Castells, M. Marzo-Castillejo, J. J. Mascort et al., "Clinical practice guideline. Prevention of colorectal cancer. 2009 update. Asociación Española de Gastroenterología," Gastroenterología y Hepatología, vol. 32, no. 10, pp. 717.el-717.e58, 2009.

[3] B. Levin, D. A. Lieberman, B. McFarland et al., "Screening and surveillance for the early detection of colorectal cancer and adenomatous polyps, 2008: a joint guideline from the american cancer society, the us multi-society task force on colorectal cancer, and the american college of radiology," Gastroenterology, vol. 134, no. 5, pp. 1570-1595, 2008.

[4] E. G. McFarland, B. Levin, D. A. Lieberman et al., "Revised colorectal screening guidelines: joint effort of the American Cancer Society, U.S. Multisociety Task Force on Colorectal Cancer, and American College of Radiology," Radiology, vol. 248, no. 3, pp. 717-720, 2008.

[5] W. S. Atkin, R. Edwards, I. Kralj-Hans et al., "Once-only flexible sigmoidoscopy screening in prevention of colorectal cancer: a multicentre randomised controlled trial," The Lancet, vol. 375, no. 9726, pp. 1624-1633, 2010.

[6] J. D. Hardcastle, J. O. Chamberlain, M. H. E. Robinson et al., "Randomised controlled trial of faecal-occult-blood screening for colorectal cancer," The Lancet, vol. 348, no. 9040, pp. 14721477, 1996.
[7] O. Kronborg, C. Fenger, J. Olsen, O. D. Jørgensen, and O. Søndergaard, "Randomised study of screening for colorectal cancer with faecal-occult-blood test," The Lancet, vol. 348, no. 9040, pp. 1467-1471, 1996.

[8] J. S. Mandel, J. H. Bond, T. R. Church et al., "Reducing mortality from colorectal cancer by screening for fecal occult blood," The New England Journal of Medicine, vol. 328, no. 19, pp. 1365-1371, 1993.

[9] S. Subramanian, M. Klosterman, M. M. Amonkar, and T. L. Hunt, "Adherence with colorectal cancer screening guidelines: a review," Preventive Medicine, vol. 38, no. 5, pp. 536-550, 2004.

[10] D. A. Joseph, J. B. King, J. W. Miller, and L. C. Richardson, "Prevalence of colorectal cancer screening among adultsbehavioral risk factor surveillance system, United States, 2010," Morbidity and Mortality Weekly Report, vol. 61, supplement, pp. 51-56, 2012.

[11] J. Swan, N. Breen, B. I. Graubard et al., "Data and trends in cancer screening in the United States: results from the 2005 National Health Interview Survey," Cancer, vol. 116, no. 20, pp. 4872-4881, 2010.

[12] J. A. Shapiro, C. N. Klabunde, T. D. Thompson, M. R. Nadel, L. C. Seeff, and A. White, "Patterns of colorectal cancer test use, including CT colonography, in the 2010 National Health Interview Survey," Cancer Epidemiology, Biomarkers \& Prevention, vol. 21, pp. 895-904, 2012.

[13] Colorectal cancer facts \& Figures 2011-2013, http://www.cancer .org/Research/CancerFactsFigures/ColorectalCancerFactsFigures/colorectal-cancer-facts-figures-2011-2013-page.

[14] S. Moss, R. Ancell-Park, and H. Brenner, "Evaluation and interpretation of screening outcomes," in European Guidelines for Quality Assurance in Colorectal Cancer Screening and Diagnosis, N. Segnan, J. Patnick, and L. von Karsa, Eds., pp. 71-102, European Union, 1st edition, 2010.

[15] M. Zavoral, S. Suchanek, F. Zavada et al., "Colorectal cancer screening in Europe," World Journal of Gastroenterology, vol. 15, no. 47, pp. 5907-5915, 2009.

[16] A. Z. Gimeno Garcia, "Factors influencing colorectal cancer screening participation," Gastroenterology Research and Practice, vol. 2012, Article ID 483417, 8 pages, 2012.

[17] T. R. Church, M. W. Yeazel, R. M. Jones et al., "A randomized trial of direct mailing of fecal occult blood tests to increase colorectal cancer screening," Journal of the National Cancer Institute, vol. 96, no. 10, pp. 770-780, 2004.

[18] N. Segnan, C. Senore, B. Andreoni et al., "Randomized trial of different screening strategies for colorectal cancer: patient response and detection rates," Journal of the National Cancer Institute, vol. 97, no. 5, pp. 347-357, 2005.

[19] T. D. Denberg, J. M. Coombes, T. E. Byers et al., "Effect of a mailed brochure on appointment-keeping for screening colonoscopy: a randomized trial," Annals of Internal Medicine, vol. 145, no. 12, pp. 895-900, 2006.

[20] R. E. Myers, R. Sifri, T. Hyslop et al., "A randomized controlled trial of the impact of targeted and tailored interventions on colorectal cancer screening," Cancer, vol. 110, no. 9, pp. 20832091, 2007.

[21] E. C. Y. Chan and S. W. Vernon, "Implementing an intervention to promote colon cancer screening through e-mail over the Internet: lessons learned from a pilot study," Medical Care, vol. 46, no. 9, pp. S117-S122, 2008.

[22] T. D. Sequist, A. M. Zaslavsky, R. Marshall, R. H. Fletcher, and J. Z. Ayanian, "Patient and physician reminders to promote 
colorectal cancer screening A randomized controlled trial," Archives of Internal Medicine, vol. 169, no. 4, pp. 364-371, 2009.

[23] J. K. Lee, V. Reis, S. Liu et al., "Improving fecal occult blood testing compliance using a mailed educational reminder," Journal of General Internal Medicine, vol. 24, no. 11, pp. 1192-1197, 2009.

[24] T. D. Sequist, A. M. Zaslavsky, G. A. Colditz, and J. Z. Ayanian, "Electronic patient messages to promote colorectal cancer screening: a randomized controlled trial," Archives of Internal Medicine, vol. 171, no. 7, pp. 636-641, 2011.

[25] K. A. Cameron, S. D. Persell, T. Brown, J. Thompson, and D. W. Baker, "Patient outreach to promote colorectal cancer screening among patients with an expired order for colonoscopy," Archives of Internal Medicine, vol. 171, no. 7, pp. 642-646, 2011.

[26] G. D. Coronado, I. Golovaty, G. Longton, L. Levy, and R. Jimenez, "Effectiveness of a clinic-based colorectal cancer screening promotion program for underserved Hispanics," Cancer, vol. 117, no. 8, pp. 1745-1754, 2011.

[27] A. Z. Doorenbos, C. Jacobsen, R. Corpuz, R. Forquera, and D. Buchwald, "A randomized controlled calendar mail-out to increase cancer screening among urban American Indian and alaska native patients," Journal of Cancer Education, vol. 26, no. 3, pp. 549-554, 2011.

[28] D. A. Leffler, N. Neeman, J. M. Rabb et al., "An alerting system improves adherence to follow-up recommendations from colonoscopy examinations," Gastroenterology, vol. 140, no. 4, pp. 1166.e3-1173.e3, 2011.

[29] A. R. Hart, T. L. Barone, S. P. Gay et al., "The effect on compliance of a health education leaflet in colorectal cancer screening in general practice in central England," Journal of Epidemiology and Community Health, vol. 51, no. 2, pp. 187-191, 1997.

[30] M. Pignone, R. Harris, and L. Kinsinger, "Videotape-based decision aid for colon cancer screening. A randomized, controlled trial," Annals of Internal Medicine, vol. 133, no. 10, pp. 761-769, 2000.

[31] L. C. Friedman, T. E. Everett, L. Peterson, K. I. Ogbonnaya, and V. Mendizabal, "Compliance with fecal occult blood test screening among low-income medical outpatients: a randomized controlled trial using a videotaped intervention," Journal of Cancer Education, vol. 16, no. 2, pp. 85-88, 2001.

[32] J. G. Dolan and S. Frisina, "Randomized controlled trial of a patient decision aid for colorectal cancer screening," Medical Decision Making, vol. 22, no. 2, pp. 125-139, 2002.

[33] J. Wardle, S. Williamson, K. McCaffery et al., "Increasing attendance at colorectal cancer screening: testing the efficacy of a mailed, psychoeducational intervention in a community sample of older adults," Health Psychology, vol. 22, no. 1, pp. 99$105,2003$.

[34] M. T. Ruffin IV and D. W. Gorenflo, "Interventions fail to increase cancer screening rates in community-based primary care practices," Preventive Medicine, vol. 39, no. 3, pp. 435-440, 2004.

[35] M. K. Campbell, A. James, M. A. Hudson et al., "Improving multiple behaviors for colorectal cancer prevention among African American church members," Health Psychology, vol. 23, no. 5, pp. 492-502, 2004.

[36] J. G. Zapka, S. C. Lemon, E. Puleo, B. Estabrook, R. Luckmann, and S. Erban, "Patient education for colon cancer screening: a randomized trial of a video mailed before a physical examination," Annals of Internal Medicine, vol. 141, no. 9, pp. 683-692, 2004.
[37] I. M. Lipkus, C. S. Skinner, J. Dement et al., "Increasing colorectal cancer screening among individuals in the carpentry trade: test of risk communication interventions," Preventive Medicine, vol. 40, no. 5, pp. 489-501, 2005.

[38] A. C. Marcus, M. Mason, P. Wolfe et al., "The efficacy of tailored print materials in promoting colorectal cancer screening: results from a randomized trial involving callers to the National Cancer Institute's Cancer Information Service," Journal of Health Communication, vol. 10, no. 1, pp. 83-104, 2005.

[39] D. P. Miller Jr., J. R. Kimberly Jr., L. D. Case, and J. L. Wofford, "Using a computer to teach patients about fecal occult blood screening: a randomized trial," Journal of General Internal Medicine, vol. 20, no. 11, pp. 984-988, 2005.

[40] M. E. Costanza, R. Luckmann, A. M. Stoddard et al., "Using tailored telephone counseling to accelerate the adoption of colorectal cancer screening," Cancer Detection and Prevention, vol. 31, no. 3, pp. 191-198, 2007.

[41] M. T. Ruffin IV, M. D. Fetters, and M. Jimbo, "Preference-based electronic decision aid to promote colorectal cancer screening: results of a randomized controlled trial," Preventive Medicine, vol. 45, no. 4, pp. 267-273, 2007.

[42] S. Percac-Lima, R. W. Grant, A. R. Green et al., "A culturally tailored navigator program for colorectal cancer screening in a community health center: a randomized, controlled trial," Journal of General Internal Medicine, vol. 24, no. 2, pp. 211-217, 2009.

[43] A. Z. Gimeno-Garcia, E. Quintero, D. Nicolas-Perez, A. ParraBlanco, and A. Jimenez, "Colorectal cancer screening in a Spanish population,” Medicina Clínica, vol. 133, pp. 736-740, 2009.

[44] A. Aragones, M. D. Schwartz, N. R. Shah, and F. M. Gany, "A randomized controlled trial of a multilevel intervention to increase colorectal cancer screening among latino immigrants in a primary care facility," Journal of General Internal Medicine, vol. 25, no. 6, pp. 564-567, 2010.

[45] S. R. Simon, F. Zhang, S. B. Soumerai et al., "Failure of automated telephone outreach with speech recognition to improve colorectal cancer screening: a randomized controlled trial," Archives of Internal Medicine, vol. 170, no. 3, pp. 264-270, 2010.

[46] K. E. Lasser, J. Murillo, S. Lisboa et al., "Colorectal cancer screening among ethnically diverse, low-income patients: a randomized controlled trial," Archives of Internal Medicine, vol. 171, no. 10, pp. 906-912, 2011.

[47] S. W. Vernon, L. K. Bartholomew, A. McQueen et al., "A randomized controlled trial of a tailored interactive computerdelivered intervention to promote colorectal cancer screening: sometimes more is just the same," Annals of Behavioral Medicine, vol. 41, no. 3, pp. 284-299, 2011.

[48] S. Misra, D. R. Lairson, W. Chan et al., "Cost effectiveness of interventions to promote screening for colorectal cancer: a randomized trial," Journal of Preventive Medicine and Public Health, vol. 44, no. 3, pp. 101-110, 2011.

[49] M. Gray and C. R. Pennington, "Screening sigmoidoscopy: a randomised trial of invitation style," Health Bulletin, vol. 58, no. 2, pp. 137-140, 2000.

[50] L. Jandorf, Y. Gutierrez, J. Lopez, J. Christie, and S. H. Itzkowitz, "Use of a patient navigator to increase colorectal cancer screening in an urban neighborhood health clinic," Journal of Urban Health, vol. 82, no. 2, pp. 216-224, 2005.

[51] C. E. Basch, R. L. Wolf, C. H. Brouse et al., "Telephone outreach to increase colorectal cancer screening in an urban minority 
population," American Journal of Public Health, vol. 96, no. 12, pp. 2246-2253, 2006.

[52] S.-P. Tu, V. Taylor, Y. Yasui et al., "Promoting culturally appropriate colorectal cancer screening through a health educator: a randomized controlled trial," Cancer, vol. 107, no. 5, pp. 959966, 2006.

[53] A. J. Dietrich, J. N. Tobin, A. Cassells et al., "Telephone care management to improve cancer screening among low-income women: a randomized, controlled trial," Annals of Internal Medicine, vol. 144, no. 8, pp. 563-571, 2006.

[54] A. J. Dietrich, J. N. Tobin, A. Cassells et al., "Translation of an efficacious cancer-screening intervention to women enrolled in a Medicaid managed care organization," Annals of Family Medicine, vol. 5, no. 4, pp. 320-327, 2007.

[55] M. L. Beach, A. B. Flood, C. M. Robinson et al., "Can languageconcordant prevention care managers improve cancer screening rates?" Cancer Epidemiology Biomarkers and Prevention, vol. 16, no. 10, pp. 2058-2064, 2007.

[56] B. J. Turner, M. Weiner, S. D. Berry, K. Lillie, K. Fosnocht, and C. S. Hollenbeak, "Overcoming poor attendance to first scheduled colonoscopy: a randomized trial of peer coach or brochure support," Journal of General Internal Medicine, vol. 23, no. 1, pp. 58-63, 2008.

[57] D. S. Blumenthal, S. A. Smith, C. D. Majett, and E. AlemaMensah, "A trial of 3 interventions to promote colorectal cancer screening in African Americans," Cancer, vol. 116, no. 4, pp. 922-929, 2010.

[58] U. Menon, R. Belue, S. Wahab et al., "A randomized trial comparing the effect of two phone-based interventions on colorectal cancer screening adherence," Annals of Behavioral Medicine, vol. 42, no. 3, pp. 294-303, 2011.

[59] B. D. Powe, E. Ntekop, and M. Barron, "An intervention study to increase colorectal cancer knowledge and screening among community elders," Public Health Nursing, vol. 21, no. 5, pp. 435$442,2004$.

[60] K. L. Braun, M. Fong, M. E. Kaanoi, M. L. Kamaka, and C. C. Gotay, "Testing a culturally appropriate, theory-based intervention to improve colorectal cancer screening among native Hawaiians," Preventive Medicine, vol. 40, no. 6, pp. 619627, 2005.

[61] A. E. Maxwell, R. Bastani, L. L. Danao, C. Antonio, G. M. Garcia, and C. M. Crespi, "Results of a community-based randomized trial to increase colorectal cancer screening among Filipino Americans," American Journal of Public Health, vol. 100, no. 11, pp. 2228-2234, 2010.

[62] P. D. Morgan, J. Fogel, I. D. Tyler, and J. R. Jones, "Culturally targeted educational intervention to increase colorectal health awareness among African Americans," Journal of Health Care for the Poor and Underserved, vol. 21, no. 3, pp. 132-147, 2010.

[63] D. Mant, A. Fuller, J. Northover et al., "Patient compliance with colorectal cancer screening in general practice," British Journal of General Practice, vol. 42, no. 354, pp. 18-20, 1992.

[64] M. F. Miller and J. G. Wong, "Reducing financial barriers enhances the return rate of stool hemoccult packets," American Journal of the Medical Sciences, vol. 306, no. 2, pp. 98-100, 1993.

[65] J. D. Freedman and C. K. Mitchell, "A simple strategy to improve patient adherence to outpatient fecal occult blood testing," Journal of General Internal Medicine, vol. 9, no. 8, pp. 462-464, 1994.

[66] L. Ore, L. Hagoel, I. Lavi, and G. Rennert, "Screening with faecal occult blood test (FOBT) for colorectal cancer: assessment of two methods that attempt to improve compliance," European Journal of Cancer Prevention, vol. 10, no. 3, pp. 251-256, 2001.

[67] R. Courtier, M. Casamitjana, F. Macià et al., "Participation in a colorectal cancer screening programme: influence of the method of contacting the target population," European Journal of Cancer Prevention, vol. 11, no. 3, pp. 209-213, 2002.

[68] M. B. Potter, L. Phengrasamy, E. S. Hudes, S. J. McPhee, and J. M. E. Walsh, "Offering annual fecal occult blood tests at annual flu shot clinics increases colorectal cancer screening rates," Annals of Family Medicine, vol. 7, no. 1, pp. 17-23, 2009.

[69] R. M. Hoffman, S. R. Steel, E. F. T. Yee et al., "A system-based intervention to improve colorectal cancer screening uptake," American Journal of Managed Care, vol. 17, no. 1, pp. 49-55, 2011.

[70] M. B. Potter, C. P. Somkin, L. M. Ackerson et al., "The FLUFIT program: an effective colorectal cancer screening program for high volume flu shot clinics," American Journal of Managed Care, vol. 17, no. 8, pp. 577-583, 2011.

[71] K. Glanz and D. B. Bishop, "The role of behavioral science theory in development and implementation of public health interventions," Annual Review of Public Health, vol. 31, pp. 399$418,2010$.

[72] V. Champion and C. S. Skinner, "The health belief model," in Health Behavior and Health Education: Theory, Research and Practice, K. Glanz, B. K. Rimer, and K. Wisnanath, Eds., pp. 4565, Jossey-Bass, San Francisco, Calif, USA, 4th edition, 2008.

[73] K. Glanz, B. K. Rimer, and K. Viswanath, Eds., Health Behavior and Health Education: Theory, Research, and Practice, JosseyBass, San Francisco, Calif, USA, 4th ed edition, 2008.

[74] G. M. Hochbaum, J. R. Sorenson, and K. Lorig, "Theory in health education practice," Health Education Quarterly, vol. 19, no. 3, pp. 295-313, 1992.

[75] R. Jepson, A. Clegg, C. Forbes, R. Lewis, A. Sowden, and J. Kleijnen, "The determinants of screening uptake and interventions for increasing uptake: a systematic review," Health Technology Assessment, vol. 4, no. 14, pp. 1-133, 2000.

[76] K. McCaffery, J. Wardle, and J. Waller, "Knowledge, attitudes, and behavioral intentions in relation to the early detection of colorectal cancer in the United Kingdom," Preventive Medicine, vol. 36, no. 5, pp. 525-535, 2003.

[77] N. B. Peterson, K. A. Dwyer, S. A. Mulvaney, M. S. Dietrich, and R. L. Rothman, "The influence of health literacy on colorectal cancer screening knowledge, beliefs and behavior," Journal of the National Medical Association, vol. 99, no. 10, pp. 1105-1112, 2007.

[78] N. K. Janz, P. A. Wren, D. Schottenfeld, and K. E. Guire, "Colorectal cancer screening attitudes and behavior: a populationbased study," Preventive Medicine, vol. 37, no. 6, pp. 627-634, 2003.

[79] B. A. Matthews, R. C. Anderson, and A. B. Nattinger, "Colorectal cancer screening behavior and health insurance status (United States)," Cancer Causes and Control, vol. 16, no. 6, pp. 735-742, 2005.

[80] V. E. Cokkinides, A. Chao, R. A. Smith, S. W. Vernon, and M. J. Thun, "Correlates of underutilization of colorectal cancer screening among U.S. adults, age 50 years and older," Preventive Medicine, vol. 36, no. 1, pp. 85-91, 2003.

[81] D. A. Fisher, K. Dougherty, C. Martin, J. Galanko, D. Provenzale, and R. S. Sandler, "Race and colorectal cancer screening: a population-based study in North Carolina," North Carolina Medical Journal, vol. 65, no. 1, pp. 12-15, 2004. 
[82] L. C. Seeff, M. R. Nadel, C. N. Klabunde et al., "Patterns and predictors of colorectal cancer test use in the adult U.S. population," Cancer, vol. 100, no. 10, pp. 2093-2103, 2004.

[83] J. A. Shapiro, L. C. Seeff, T. D. Thompson, M. R. Nadel, C. N. Klabunde, and S. W. Vernon, "Colorectal cancer test use from the 2005 National Health Interview Survey," Cancer Epidemiology Biomarkers and Prevention, vol. 17, no. 7, pp. 16231630, 2008.

[84] A. Z. Gimeno-García, E. Quintero, D. Nicolás-Pérez, and A. Jiménez-Sosa, "Public awareness of colorectal cancer and screening in a Spanish population," Public Health, vol. 125, no. 9, pp. 609-615, 2011.

[85] L. A. Pollack, D. K. Blackman, K. M. Wilson, L. C. Seeff, and M. R. Nadel, "Colorectal cancer test use among Hispanic and nonHispanic U.S. populations," Preventing Chronic Disease, vol. 3, no. 2, article A50, 2006.

[86] T. M. James, K. A. Greiner, E. F. Ellerbeck, C. Feng, and J. S. Ahluwalia, "Disparities in colorectal cancer screening: a guideline-based analysis of adherence," Ethnicity and Disease, vol. 16, no. 1, pp. 228-233, 2006.

[87] M. K. Paasche-Orlow and M. S. Wolf, "The causal pathways linking health literacy to health outcomes," American Journal of Health Behavior, vol. 31, supplement 1, pp. s19-s26, 2007.

[88] C. Von Wagner, K. Knight, A. Steptoe, and J. Wardle, "Functional health literacy and health-promoting behaviour in a national sample of British adults," Journal of Epidemiology and Community Health, vol. 61, no. 12, pp. 1086-1090, 2007.

[89] H. I. Meissner, N. Breen, C. N. Klabunde, and S. W. Vernon, "Patterns of colorectal cancer screening uptake among men and women in the United States," Cancer Epidemiology Biomarkers and Prevention, vol. 15, no. 2, pp. 389-394, 2006.

[90] A. Afable-Munsuz, S.-Y. Liang, N. A. Ponce, and J. M. E. Walsh, "Acculturation and colorectal cancer screening among older Latino adults: differential associations by national origin," Journal of General Internal Medicine, vol. 24, no. 8, pp. 963-970, 2009.

[91] J. A. Diaz, M. B. Roberts, R. E. Goldman, S. Weitzen, and C. B. Eaton, "Effect of language on colorectal cancer screening among Latinos and non-Latinos," Cancer Epidemiology Biomarkers and Prevention, vol. 17, no. 8, pp. 2169-2173, 2008.

[92] C. N. Klabunde, D. Lanier, E. S. Breslau et al., "Improving colorectal cancer screening in primary care practice: innovative strategies and future directions," Journal of General Internal Medicine, vol. 22, no. 8, pp. 1195-1205, 2007.

[93] C. N. Klabunde, D. Lanier, M. R. Nadel, C. McLeod, G. Yuan, and S. W. Vernon, "Colorectal cancer screening by primary care physicians. recommendations and practices, 2006-2007," American Journal of Preventive Medicine, vol. 37, no. 1, pp. 8-16, 2009.

[94] G. Rees, P. R. Martin, and F. A. MacRae, "Screening participation in individuals with a family history of colorectal cancer: a review: review paper," European Journal of Cancer Care, vol. 17, no. 3, pp. 221-232, 2008.

[95] A. Z. Gimeno García, E. Quintero, D. Nicolás Pérez, M. Hernández, and A. Jiménezsosa, "Colorectal cancer screening in first-degree relatives of colorectal cancer: participation, knowledge, and barriers against screening," European Journal of Gastroenterology and Hepatology, vol. 23, no. 12, pp. 1165-1171, 2011.

[96] M. F. Weber, E. Banks, R. Ward, and F. Sitas, "Population characteristics related to colorectal cancer testing in New South
Wales, Australia: results from the 45 and Up Study cohort," Journal of Medical Screening, vol. 15, no. 3, pp. 137-142, 2008.

[97] C. H. M. Van Jaarsveld, A. Miles, R. Edwards, and J. Wardle, "Marriage and cancer prevention: does marital status and inviting both spouses together influence colorectal cancer screening participation?" Journal of Medical Screening, vol. 13, no. 4, pp. 172-176, 2006.

[98] B. B. Green, A. Bogart, J. Chubak et al., "Nonparticipation in a population-based trial to increase colorectal cancer screening," American Journal of Preventive Medicine, vol. 42, no. 4, pp. 390397, 2012.

[99] S. W. Vernon, "Participation in colorectal cancer screening: a review," Journal of the National Cancer Institute, vol. 89, no. 19, pp. 1406-1422, 1997.

[100] E. Power, A. Miles, C. Von Wagner, K. Robb, and J. Wardle, "Uptake of colorectal cancer screening: system, provider and individual factors and strategies to improve participation," Future Oncology, vol. 5, no. 9, pp. 1371-1388, 2009.

[101] R. E. Myers, E. Ross, C. Jepson et al., "Modeling adherence to colorectal cancer screening," Preventive Medicine, vol. 23, no. 2, pp. 142-151, 1994.

[102] S. Tong, K. Hughes, B. Oldenburg, C. Del Mar, and B. Kennedy, "Socio-demographic correlates of screening intention for colorectal cancer," Australian and New Zealand Journal of Public Health, vol. 24, no. 6, pp. 610-614, 2000.

[103] G. C. Harewood, M. J. Wiersema, and L. J. Melton III, "A prospective, controlled assessment of factors influencing acceptance of screening colonoscopy," American Journal of Gastroenterology, vol. 97, no. 12, pp. 3186-3194, 2002.

[104] K. A. Robb, I. Solarin, E. Power, W. Atkin, and J. Wardle, "Attitudes to colorectal cancer screening among ethnic minority groups in the UK," BMC Public Health, vol. 8, article 34, 2008.

[105] S. S. Gorin, "Correlates of colorectal cancer screening compliance among urban hispanics," Journal of Behavioral Medicine, vol. 28, no. 2, pp. 125-137, 2005.

[106] M. T. Kiviniemi, A. Bennett, M. Zaiter, and J. R. Marshall, "Individual-level factors in colorectal cancer screening: a review of the literature on the relation of individual-level health behavior constructs and screening behavior," Psycho-Oncology, vol. 20, no. 10, pp. 1023-1033, 2011.

[107] J. Wardle, S. Sutton, S. Williamson et al., "Psychosocial influences on older adults' interest in participating in bowel cancer screening," Preventive Medicine, vol. 31, no. 4, pp. 323-334, 2000.

[108] E. M. Santos, M. T. Lourenco, and B. M. Rossi, "Risk perception among Brazilian individuals with high risk for colorectal cancer and colonoscopy," Hereditary Cancer in Clinical Practice, vol. 9, article 4, 2011.

[109] Z. Berkowitz, N. A. Hawkins, L. A. Peipins, M. C. White, and M. R. Nadel, "Beliefs, risk perceptions, and gaps in knowledge as barriers to colorectal cancer screening in older adults," Journal of the American Geriatrics Society, vol. 56, no. 2, pp. 307-314, 2008.

[110] A. Z. Gimeno-García, E. Quintero, D. Nicolás-Pérez, A. ParraBlanco, and A. Jiménez-Sosa, "Impact of an educational videobased strategy on the behavior process associated with colorectal cancer screening: a randomized controlled study," Cancer Epidemiology, vol. 33, no. 3-4, pp. 216-222, 2009.

[111] R. Stacy, W. A. Torrence, and C. R. Mitchell, "Perceptions of knowledge, beliefs, and barriers to colorectal cancer screening," Journal of Cancer Education, vol. 23, no. 4, pp. 238-240, 2008. 
[112] I. Guessous, C. Dash, P. Lapin, M. Doroshenk, R. A. Smith, and C. N. Klabunde, "Colorectal cancer screening barriers and facilitators in older persons," Preventive Medicine, vol. 50, no. 1-2, pp. 3-10, 2010.

[113] R. A. Breslow, B. K. Rimer, R. C. Baron et al., "Introducing the community guide's reviews of evidence on interventions to increase screening for breast, cervical, and colorectal cancers," American Journal of Preventive Medicine, vol. 35, no. 1, pp. S14S20, 2008.

[114] J. M. E. Walsh and J. P. Terdiman, "Colorectal cancer screening: clinical applications," Journal of the American Medical Association, vol. 289, no. 10, pp. 1297-1302, 2003.

[115] C. L. Stokamer, C. T. Tenner, J. Chaudhuri, E. Vazquez, and E. J. Bini, "Randomized controlled trial of the impact of intensive patient education on compliance with fecal occult blood testing," Journal of General Internal Medicine, vol. 20, no. 3, pp. 278-282, 2005. 


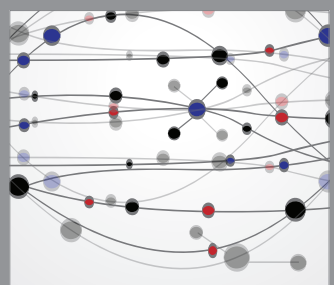

The Scientific World Journal
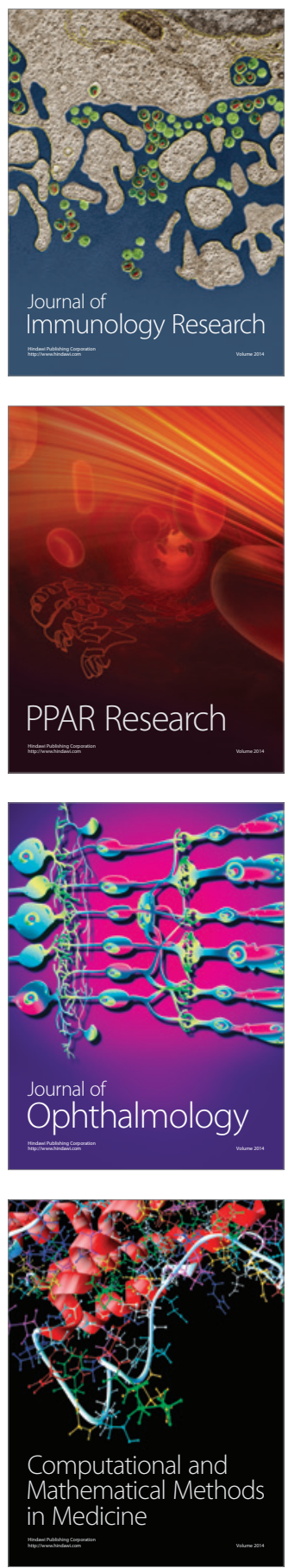

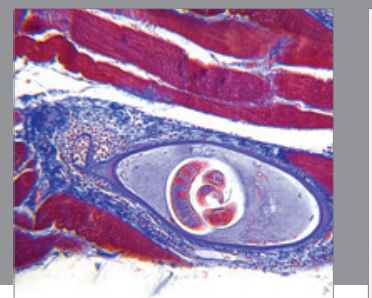

Gastroenterology

Research and Practice
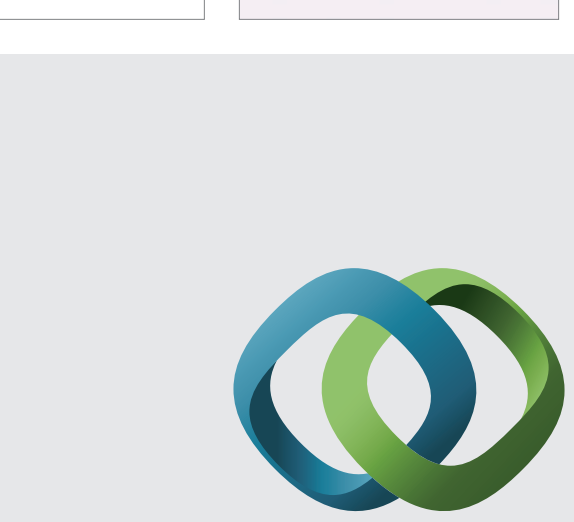

\section{Hindawi}

Submit your manuscripts at

http://www.hindawi.com
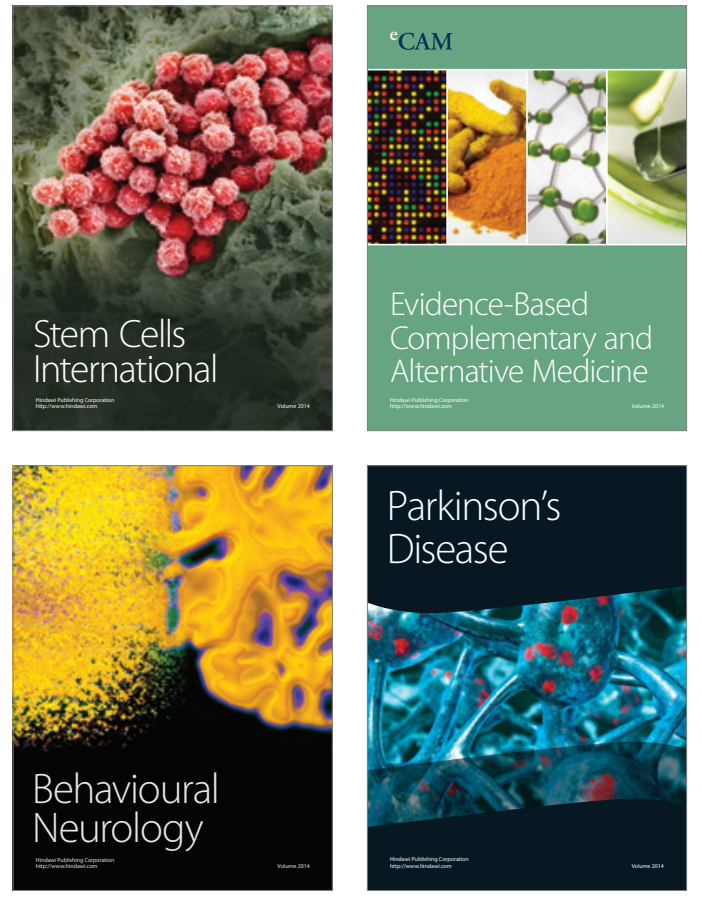
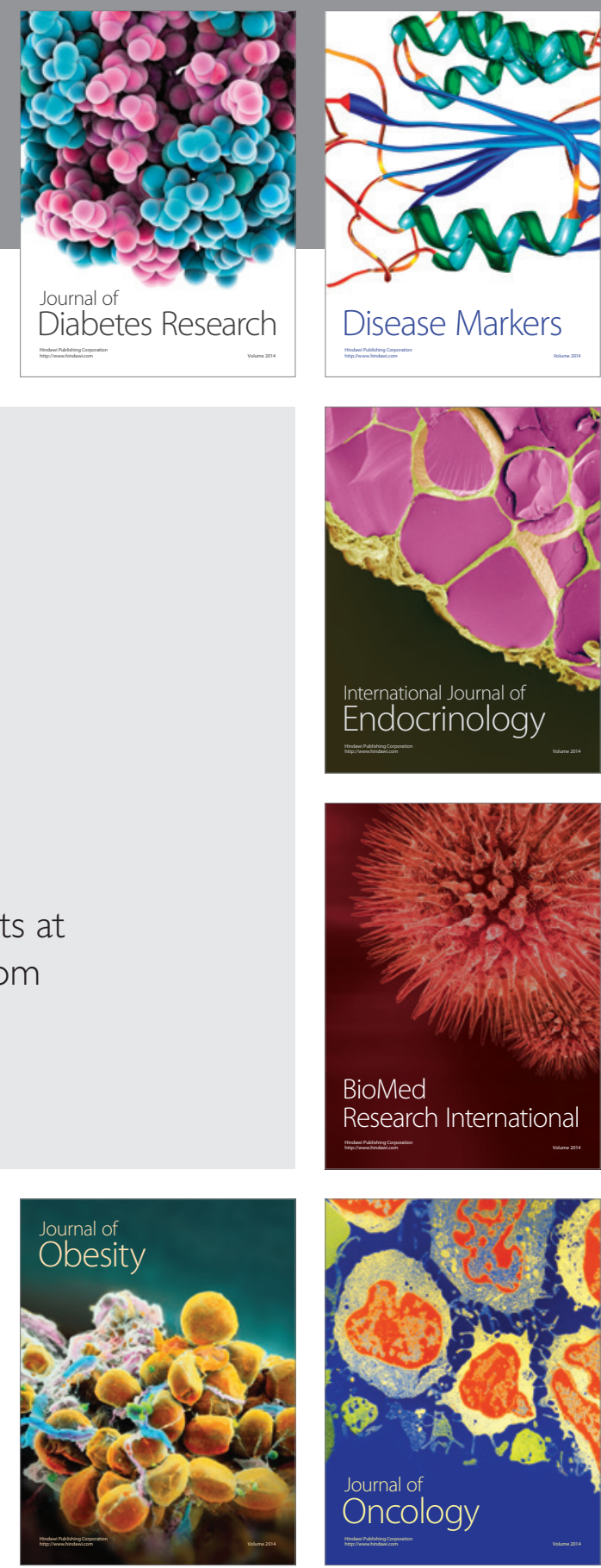

Disease Markers
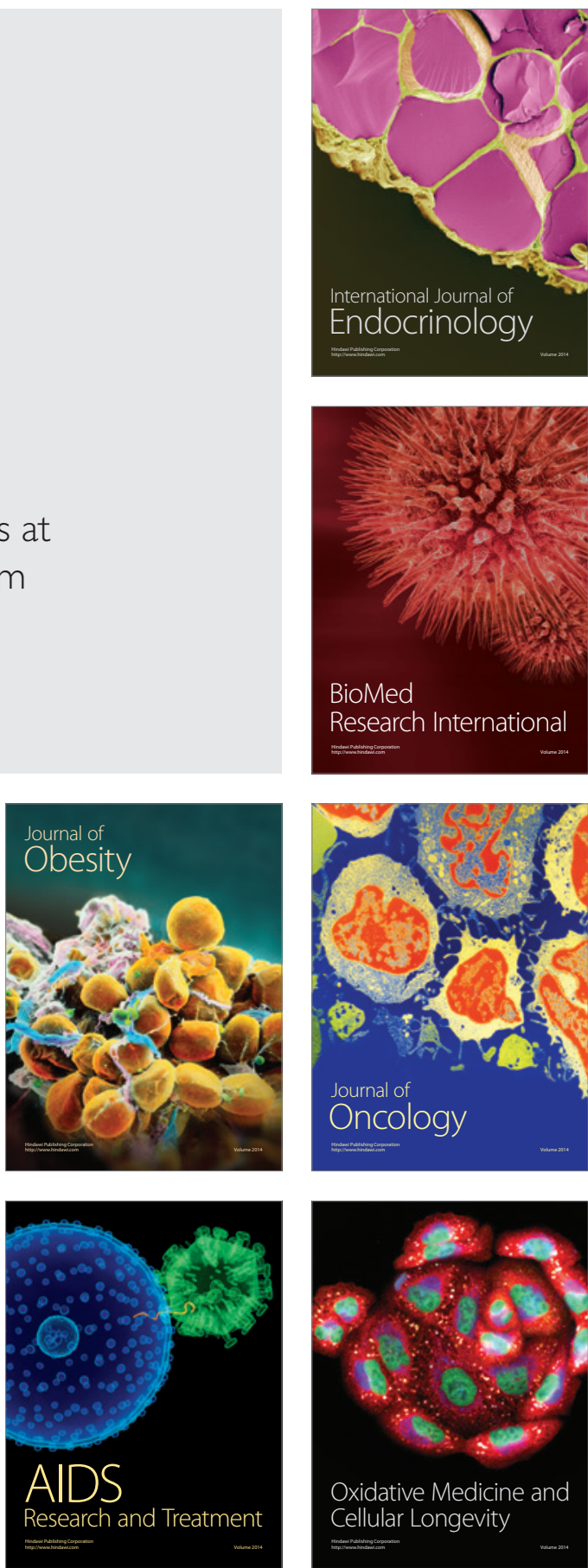